\title{
Relaciones topológicas en toba del oeste (guaycurú, Formosa, Argentina)
}

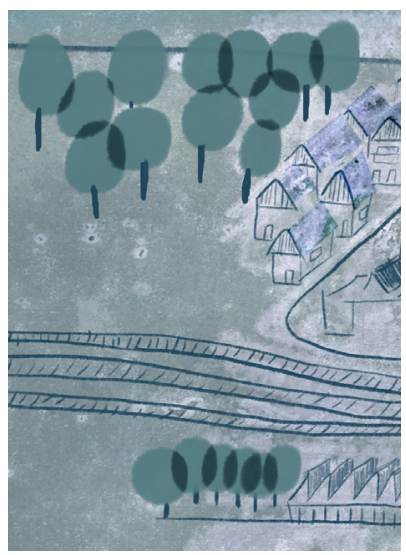

\author{
María Belén Carpio \\ Instituto de Investigaciones Geohistóricas (CONICET/UNNE), \\ Consejo Nacional de Investigaciones Científicas y Técnicas, Argentina \\ Universidad Nacional del Nordeste, Argentina \\ belenvenado@yahoo.com.ar/belencarpio@conicet.gov.ar
}

\begin{abstract}
Resumen
La topología o estasis no angular es un subdominio semántico del espacio en el cual existe una coincidencia entre la figura y el fondo, es decir, se relacionan por proximidad, contacto y/o contención. La variación puede observarse en las distinciones conceptuales que se efectúan y en la manera en la que son expresadas en las lenguas (Levinson y Wilkins 2006, 15-22, 513-519). En este trabajo, se analizan las construcciones locativas que se utilizan, de manera preponderante, para codificar la función locativa básica o responder preguntas del tipo ¿dónde está X? en toba del oeste de Formosa (Argentina). Específicamente, se estudian los verbos locativos con raíces posicionales, los sufijos locativos y los lexemas espaciales. A su vez, se demuestra que la adhesión de la figura respecto del fondo y los medios a través de los cuales se lleva a cabo la misma inciden en la construcción morfosintáctica seleccionada. El corpus está compuesto por datos provenientes de entrevistas realizadas a hablantes de toba que residen en Vaca Perdida (Departamento Bermejo, provincia de Formosa, Argentina) a partir del estímulo visual Topological Relations Picture Series (Bowerman y Pederson 1992).
\end{abstract}

\section{Topological Relations in Western Toba (Guaicuruan, Formosa, Argentina)}

\begin{abstract}
Topology or non-angular stasis is a spatial semantic subdomain in which there is coincidence between figure and ground. They are related by proximity, contact and/or containment. Languages differ in what conceptual distinctions are made within this subdomain, and how they are encoded (Levinson and Wilkins 2006, 15-22, 513-519).This paper analyzes the locative constructions mainly used to encode the basic locative function or to answer "where is $\mathrm{X}$ " questions in Toba from Western Formosa (Argentina). Thus, locative verbs
\end{abstract}

Palabras clave

Estasis no angular raíces posicionales adhesión lexemas espaciales guaycurú

\section{Keywords}

Non-angular stasis positional roots adhesion spatial lexemes Guaicuruan 
with positional roots, locative suffixes and spatial lexemes are described. In addition, it is demonstrated that adhesion between figure and ground and the means that perform it condition the morphosyntactic constructions selected. The analysis is based on elicitation sessions with the visual stimulus Topological Relations Picture Series (Bowerman and Pederson 1992) in Vaca Perdida (Bermejo Department, Formosa Province, Argentina).

\section{Relações topológicas em Toba ocidental (Guaycurú, Formosa, Argentina)}

\section{Resumo}

Topologia ou estase não angular é um subdomínio semântico do espaço no qual há uma coincidência entre a figura e o fundo, ou seja, estão relacionados por proximidade, contato e/ou contenção. A variação pode ser observada nas distinções conceituais que são feitas e na maneira como elas são expressas nas línguas (Levinson e Wilkins 2006, 15-22, 513-519). Neste trabalho, analisamos as construções locativas que são utilizadas, de forma preponderante, para codificar a função locativa básica ou responder questões do tipo, onde é X? em Toba do oeste do Formosa (Argentina). Especificamente, os verbos locativos com raízes posicionais, sufixos locativos e lexemes espaciais são estudados. Por sua vez, mostra-se que a adesão da figura ao fundo e os meios pelos quais ela é realizada afetam a construção morfossintática selecionada. O corpus é composto por dados de entrevistas com falantes de Toba que residem na Vaca Perdida (Departamento de Bermejo, província de Formosa, Argentina) a partir do estímulo visual Topological Relations Picture Series (Bowerman e Pederson 1992).

\section{Introducción}

En este trabajo se analiza el subdominio espacial topológico en toba del oeste de Formosa. De este modo, se describen las construcciones morfosintácticas que se utilizan, de manera preponderante, para codificar situaciones en las cuales la figura y el fondo están en contigüidad o en gran proximidad y las distinciones angulares no son requeridas ni relevantes. Se presta especial atención al condicionamiento semántico espacial (soporte horizontal, vertical, adhesión, contención plena o parcial, vestimenta/adorno, marca en la superficie, etc.) en el uso de los verbos locativos (raíces posicionales y sufijos locativos), los lexemas espaciales y el recurso a otras estrategias morfosintácticas, tales como verbos de adhesión, construcción existencial afirmativa y yuxtaposición nominal.

El análisis del subdominio espacial topológico en toba del oeste de Formosa es realizado siguiendo lo propuesto desde la perspectiva de la tipología semántica por Levinson (1996), Levinson y Wilkins (2006), Ameka y Levinson (2007), Brown (2006), entre otros. Estos autores analizan las conceptualizaciones espaciales translingüísticamente utilizando las distinciones formales como claves para acceder a la estructura del dominio semántico del espacio. Esta perspectiva teórica requiere una metodología comparativa controlada a través de la aplicación de los mismos estímulos o herramientas cuidadosamente diseñadas de elicitación, como por ejemplo la utilizada en la recolección del corpus de este trabajo Topological relations Picture Series (TRPS) (Bowerman y Pederson 1992). 
Si bien este trabajo posee una proyección en términos comparativos con investigaciones en otras lenguas del mundo acerca de las relaciones topológicas a partir del mismo estímulo visual, el objetivo central de la investigación es de índole descriptivo y se restringe al estudio de topología en toba del oeste de Formosa, lengua perteneciente a la familia guaycurú.

En las lenguas guaycurúes, en lo que respecta al dominio espacial, la categoría de los demostrativos ha sido ampliamente estudiada: mocoví (Grondona 1998a; Gualdieri 1998, 2006), toba hablado en la provincia de Chaco (Buckwalter 1980; Klein 1981a; Censabella 2001; Klein y Messineo 2003; Cúneo 2013), toba del este de Formosa (González 2015a), toba del oeste de Formosa (Carpio 2011), pilagá (Vidal 2001), caduveo (Sandalo 1995) y abipón (Najlis 1966). En relación a la codificación de nociones espaciales en los verbos, han recibido especial atención los sufijos locativo/direccionales en términos de su comportamiento o no como aplicativos y de procesos de gramaticalización en toba de la provincia de Chaco (Censabella 2007, 2011; González 2010, 2011; Messineo 2019), toba del este de Formosa (González 2015b) y mocoví (Carrió 2011), y de su forma, significado y distribución, en perspectiva comparada (Grondona 1998b), y en toba de la provincia de Chaco (Klein 1981b). Los estudios de las propiedades semánticas de los predicados locativos, considerados íntegramente, no son numerosos en lenguas de esta familia: toba de la provincia de Chaco (Messineo y Klein 2005, 2007) y mocoví (Carrió 2011). En ambas lenguas el tema ha sido abordado, fundamentalmente, a partir de la propuesta de Talmy (1985, 2000), con especial atención a la expresión de la trayectoria en verbos de movimiento y posición y a la codificación de la locación y la dirección del movimiento. En este trabajo, además de la descripción de las construcciones que permiten codificar relaciones topológicas en toba del oeste de Formosa, se demuestra el condicionamiento semántico en la selección de las raíces posicionales, la incidencia de la adhesión de la figura respecto del fondo y los medios a través de los cuales se lleva a cabo en la estrategia morfosintáctica seleccionada, y la codificación de una relación parte-todo o de una locación relativa dependiendo de la posición de los lexemas espaciales en la construcción locativa.

El artículo se estructura de la siguiente manera. En la sección 2 se presentan datos acerca del pueblo toba del oeste de Formosa y se describe la estructura gramatical de la lengua en la medida en que resulta pertinente para la descripción espacial. En la sección 3 se describe el corpus analizado y la metodología utilizada. En la sección 4 se presenta el marco teórico de la tipología semántica con especial atención a las relaciones topológicas. En la sección 5 se analiza la construcción locativa más extendida en el corpus analizado, es decir, aquella cuyos verbos están compuestos por raíces posicionales y sufijos locativos. A su vez, se describe el uso de lexemas espaciales que permiten, de acuerdo con su posición en la cláusula, codificar una relación locativa o especificar una parte del fondo. En la sección 6 se estudian construcciones morfosintácticas alternativas que codifican relaciones topológicas en las que la figura se encuentra adherida al fondo o se trata de una persona de pie sobre el fondo. Finalmente, en la sección 7, se presentan conclusiones y perspectivas de investigación a futuro.

\section{Toba del oeste de Formosa}

Las diferentes dinámicas de contacto de los actuales tobas del oeste de Formosa con otros pueblos indígenas y con la población criolla permiten 
explicar la mutua (in)inteligibilidad entre variedades de toba y en relación con otras lenguas de la familia guaycurú. Es decir, las variedades lingüísticas habladas en el este y centro-este de Formosa, por un lado, y en el oeste de dicha provincia, por el otro, son mutuamente ininteligibles. La mutua inteligibilidad se observa entre las variedades habladas por los tobas en el este y centro-este de Formosa y en la provincia de Chaco, y entre los tobas del oeste formoseño y los pilagás (Mendoza y Wright 1989, 245).

Los tobas del oeste formoseño habitan en comunidades ubicadas sobre la ribera derecha del río Pilcomayo y una parte de la población vive en el "Barrio Toba" en las periferias de Ingeniero G. N. Juárez en la provincia de Formosa (Arenas 2003) (mapa 1). Son un grupo de aproximadamente 1800 personas, se autodenominan qomlé?k y se consideran a sí mismos como "tobas". Los pilagás nombran a los tobas del oeste de Formosa ñachilamóle? $k$ "la gente de las nacientes del río" y estos denominan a los pilagás tayéñile?k "la gente de río abajo".

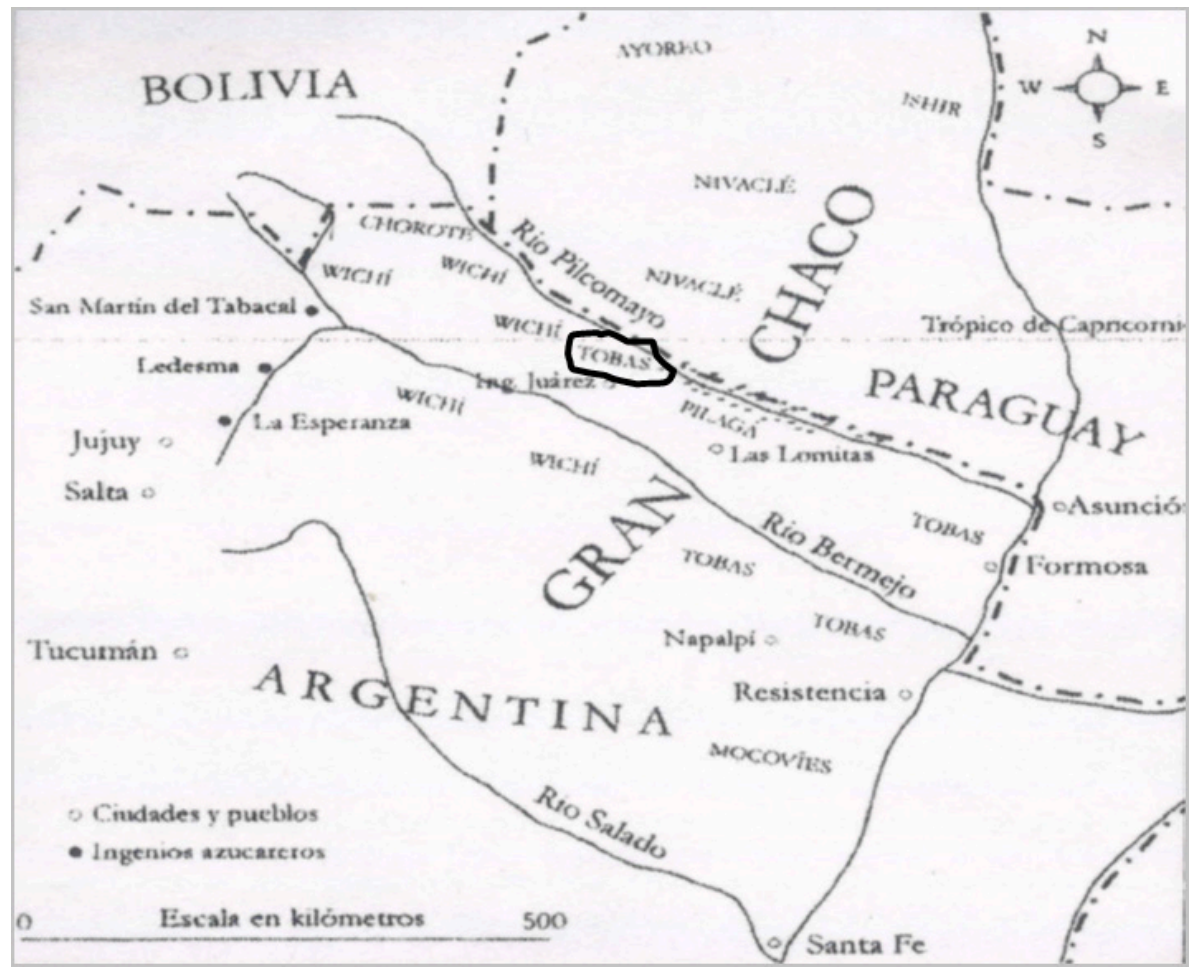

Mapa 1. Localización geográfica de los tobas del oeste de Formosa (adaptado de Gordillo 2006, 13).

La lengua hablada por los grupos tobas del oeste de Formosa se caracteriza por una tendencia a la polisíntesis y a la aglutinación; tanto en los constituyentes de la frase nominal como de la frase verbal se observa una preferencia por el uso de sufijos. Cuenta con seis raíces demostrativas que se anteponen al nombre que modifican y expresan rasgos estáticos — sentado, parado, acostado $^{1}$, ausente, próximo al centro deíctico-y dinámicos —alejándose del centro deíctico y acercándose al centro deíctico- de los referentes nominales. A estas raíces demostrativas se pueden adicionar sufijos que codifican la distinción entre exofórico (visible o no-visible) y endofórico, pueden funcionar adnominal y pronominalmente, y reciben flexión de género y número. A su vez, las raíces demostrativas junto al prefijo ho- 'baja certeza subjetiva del hablante' y pospuestas al elemento modificado expresan modalidad epistémica. Se
1. Puede expresar, además, un rasgo cualitativo del referente nominal como 'difunto'. 
distingue entre posesión alienable e inalienable mediante afijos en el nombre poseído, los cuales, a su vez, expresan persona y número del poseedor (Carpio 2012, 44-55, 73-81; Carpio y González 2017,138-143).

La lengua estudiada no posee adposiciones ni marcación de caso. Los índices pronominales verbales que codifican el argumento único de una cláusula intransitiva (S) y el argumento más parecido al agente de una cláusula transitiva (A) requieren opcionalmente la presencia de un nombre o pronombre libre co-referente (conominal). En cambio, solo se indexa el número del argumento más parecido al paciente $(\mathrm{P})$ en el verbo y se requiere obligatoriamente un conominal en función P. Existen tres tipos de índices pronominales - tipo I, II y III- cuya selección está, en general, determinada desde el lexicón. Particularmente relevantes para este trabajo son los índices pronominales tipo I resaltados en negrita en el cuadro 1, puesto que son los que ocurren con los verbos que codifican relaciones topológicas (Carpio 2012, 103-131, 2016).

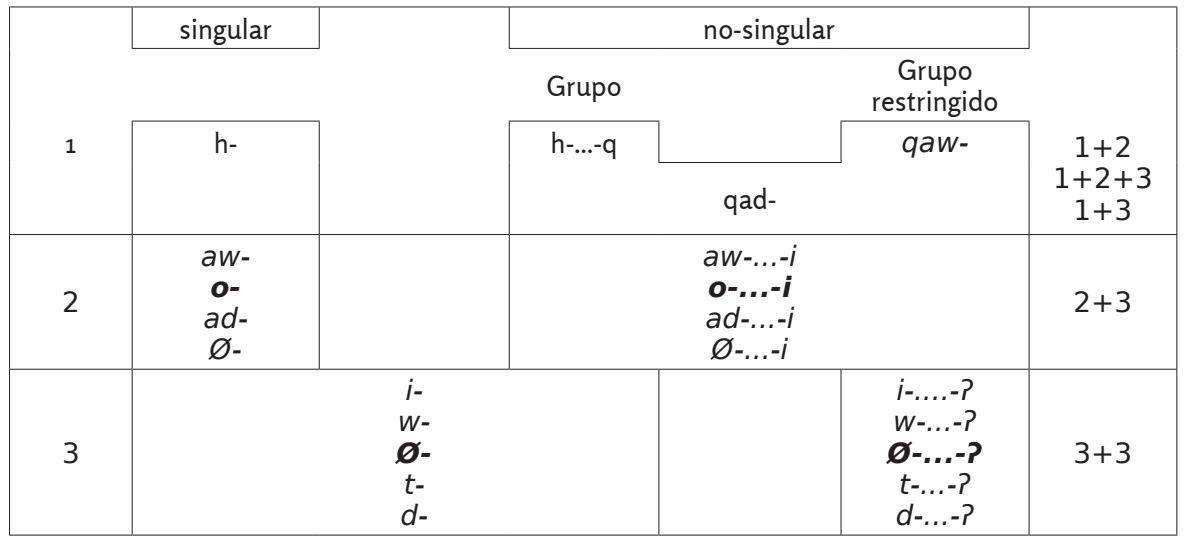

Cuadro 1. Índices pronominales tipo I que codifican S y A en toba del oeste de Formosa.

En toba del oeste de Formosa existen, de acuerdo con sus compatibilidades sintácticas, dos tipos de sufijos verbales que permiten codificar locación. Los sufijos locativos tipo I no requieren la presencia de un conominal que codifique el fondo o la meta, mientras que los sufijos locativos tipo II exigen que se codifique a través de un pronombre libre o de una frase nominal el fondo o la meta. Los sufijos locativos registrados en el corpus analizado están resaltados en negrita en el cuadro 2.

\begin{tabular}{|lll|}
\hline Sufijos locativos tipo I & hacia abajo & -ñi \\
& hacia arriba & -hegem \\
& hacia el interior & - wo \\
& hacia el agua & -hom \\
\hline Sufijos locativos tipo II & en medio de, contención total & -we \\
& hacia & - a \\
sobre & - lege \\
dentro, adherido & - -yi \\
dentro, contención parcial & - gi \\
alrededor & - hop \\
debajo & - Pot \\
acercándose & - get \\
alejándose & $-g e$ \\
\hline
\end{tabular}

Cuadro 2. Sufijos locativos en toba del oeste de Formosa. 


\section{Corpus y metodología}

El corpus analizado surge de entrevistas realizadas a cuatro hablantes varones adultos de toba del oeste de Formosa, a partir del estímulo visual de libre acceso denominado Topological Relations Picture Series (Bowerman y Pederson 1992), específicamente diseñado para el estudio de este subdominio topológico, adaptándolo al contexto de la comunidad de Vaca Perdida (Departamento Bermejo, Formosa). Este estímulo visual está compuesto por imágenes con dos objetos, uno de los cuales se señala con una flecha como la figura y el otro es el fondo. Las 71 imágenes que lo componen contrastan, como plantean Levinson y Wilkins (2006, 9-10), en una serie de dimensiones que se yuxtaponen parcialmente: soporte horizontal, soporte vertical (suspendido), adhesión, adhesión a un líquido o con masilla, marca en la superficie, criatura viviente sobre una superficie no-horizontal, acoplamiento de una figura saliente a un fondo, acoplamiento mediante una cuerda, circunvalación, envoltura, vestimenta/adorno, contención plena o parcial, contención en líquido o masa, contención en un límite que rodea, adhesión a través de perforación, espacios negativos (agujeros, rajaduras), ausencia de contacto vertical, detrás de, enfrente de, debajo de y al lado.

Los hablantes consultados respondieron a la pregunta "¿dónde está X (figura)?" y algunos de ellos formularon no solo la respuesta sino también la pregunta en su lengua. El análisis se complementó con textos libres y datos provenientes del Vocabulario toba (Tebboth 1943).

\section{Marco teórico}

El análisis de las construcciones locativas que se desarrolla a continuación está basado en lo propuesto por Levinson y Wilkins (2006), Ameka y Levinson (2007), Wilkins (2006), y Brown (2006), entre otros, desde la perspectiva de la tipología semántica. Desde este enfoque teórico-metodológico, translingüísticamente, las distinciones formales constituyen claves para acceder a la estructura del dominio semántico del espacio. Como plantean Levinson y Wilkins (2006, 15-22, 513-519), dentro del dominio semántico del espacio, es posible establecer una primera gran distinción entre dos subdominios: estasis y kinesis. Dentro del subdominio estasis, distinguen dos tipos de relaciones estáticas entre entidades: (i) no angular o topología cuando existe una coincidencia entre la figura entidad que es situada o localizada y el fondo punto de referencia respecto del cual se sitúa la figura y se relacionan por proximidad, contacto o contención; y (ii) angular o marcos de referencia que funcionan como sistemas de coordenadas intrínsecos, relativos y/o absolutos, donde resulta pertinente, además de la figura y el fondo, el ancla (anchor) o punto cero a partir del cual es calculado el vector que limita el espacio de búsqueda desde el fondo a la figura. En el subdominio kinesis puede codificarse el movimiento deíctico, el movimiento para el logro de una meta, y/o la manera del movimiento. La variación puede observarse en cada uno de los subdominios en las distinciones conceptuales que se efectúan y en la manera en la que son expresadas en las lenguas.

Específicamente en lo que respecta a la estasis no angular o topología, las lenguas difieren en la estructura de la construcción utilizada para codificar la función locativa básica, es decir, aquella que ocurre, de manera preponderante, para responder preguntas del tipo “¿dónde está X?". Translingüísticamente, las adposiciones presentan distintos grados de 
transparencia acerca de las propiedades de la figura y el fondo y no son necesariamente el locus preferido de codificación de las distinciones espaciales; algunas lenguas no poseen adposiciones y utilizan marcación de caso y/o nominales espaciales, otras poseen un pequeño número de verbos locativos como "estar parado", "estar sentado", "estar acostado" y/o "estar colgado" - por ejemplo, holandés (indoeuropea, Holanda) (Van Staden et al. 2006), yélî dnye (aislada, Papúa Nueva Guinea) (Levinson 2006), arrernte (pama-nyungana, Australia) (Wilkins 2006), y kilivila (austronésica, Papúa Nueva Guinea) (Senft 2006), entre otras-, y otras poseen un conjunto más amplio de verbos disposicionales que codifican rasgos de forma configuración, animacidad, consistencia, textura, etc. de la figura-y son seleccionados de acuerdo a la orientación y disposición precisa de la misma con respecto al fondo - por ejemplo, tzeltal (maya, México) (Brown 2006), entre otras-.

Levinson y Wilkins $(2006,16,515)$ sostienen que la identificación de la construcción locativa básica se basa en un tipo de escena prototípico constituido por un objeto movible en una superficie restringida, como puede ser una taza sobre una mesa, y describen dos dimensiones de variación topológica que alejan el recurso a la construcción locativa básica. Estas son: (i) variación en los rasgos de la escena prototípica en que una figura objeto relativamente pequeña, manipulable, inanimada, movible e independiente se encuentra contigua a un objeto fondo relativamente amplio, relativamente estacionario (fijado o inmóvil); y (ii) variación en el contacto. Cuando disminuye y hay mayor espacio entre la figura y el fondo, existen mayores probabilidades de que se recurra a una construcción distinta a la construcción locativa básica. De este modo, tenderán a ser codificadas mediante la construcción locativa básica escenas como una taza sobre la mesa, una fruta en una ensaladera por sobre un anillo en un dedo o una flecha atravesando una manzana. En el análisis de los datos en toba del oeste de Formosa resultó relevante la variación en el contacto entre figura y fondo para recurrir a una estrategia morfosintáctica alternativa en la que no se utilizan los verbos posicionales, sino verbos de adhesión.

En lo que respecta a los verbos posicionales, Ameka y Levinson $(2007,859)$ plantean que, translingüísticamente, su uso - junto a la fuente parcialmente basada en la postura humana - está parcial o ampliamente determinado por las propiedades geométricas abstractas de la figura. Por ejemplo, el uso de los verbos posicionales es probable que esté basado en la orientación del eje máximo del objeto cuando se encuentra en la posición canónica (es decir, en la que un objeto ocurre normalmente, es utilizado o guardado): "estar parado" (stand), cuando el eje largo es canónicamente vertical; "estar acostado" (lie), cuando el eje largo es canónicamente horizontal; "estar sentado" (sit), cuando no hay eje principal o el objeto posee una amplia base en su posición canónica; y "estar colgado" (hang), cuando no posee soporte por debajo. Por ejemplo, en las lenguas zapotecas modernas, según Lillehaugen y Sonnenschein (2012, 24-26), los verbos posicionales, cuando son utilizados con figuras animadas, se corresponden con la postura o pose de la figura, mientras que, cuando se trata de figuras inanimadas, el cambio de verbo posicional resulta en una construcción agramatical.

Por su parte, Newman $(2002,1-3)$ describe cuatro propiedades que constituyen el marco semántico de los verbos "estar sentado", "estar parado" y "estar acostado": 
(i) Dominio espaciotemporal. Se refiere a toda la configuración espacial que se mantiene a través del tiempo. En cada una de las posturas se da una fuerte extensión a través del tiempo y un contraste entre las configuraciones espaciales implicadas: una forma compacta asociada ("estar sentado"), una elongación erguida, vertical ("estar parado") y una elongación horizontal ("estar acostado").

(ii) Dominio de la fuerza dinámica. Se refiere a la manera en que las entidades ejercen fuerza o son sujetas a fuerzas. Si bien los tres estados pueden mantenerse sin movimiento físico de parte de la persona involucrada, existen diferencias entre ellos en lo que respecta al control sensorio-motriz que es necesario para mantener la posición. La graduación en términos del grado de control requerido, en orden decreciente, es: "estar parado", "estar sentado", "estar acostado".

(iii)Zona activa asociada con cada predicado. Se refiere a la subparte más prominente que está más directamente implicada en la interacción de entidades o en el mantenimiento de un estado. Las nalgas y, en alguna medida el torso alto, son cruciales para mantener la posición sentada, las piernas y el torso alto lo son para asumir una postura vertical, y para acostarse la zona activa es el lado del cuerpo que entra en contacto con una superficie plana.

(iv) Dominio sociocultural. en términos de la compatibilidad con la actividad física, "estar sentado" es una posición relativamente confortable tanto para el trabajo como para la relajación, "estar parado" es una posición físicamente más poderosa puesto que permite una visión a gran distancia y es un prerrequisito para caminar, correr, etc., y "estar acostado" es la posición menos compatible con la acción física y está asociado con el reposo, el sueño, la enfermedad y la muerte.

A través de la comparación translingüística controlada, es decir, a partir de datos recolectados en distintas lenguas mediante el mismo estímulo visual, Levinson y Wilkins (2006, 526), describen el subdominio topológico como un espacio de similitud estructurado que es repetidamente validado mediante diferentes tipos de distinciones lingüísticas — distinciones entre la construcción locativa básica y recursos dentro de la misma y otro tipo de construcciones, entre sistemas adposicionales y distinciones realizadas a través de predicados locativos contrastivos-. Debajo de esta similitud espacial ocurren nociones intensionales, ordenadas de las más generales a las más específicas, como: estasis, contacto, contención, posición vertical, contacto de superficie a superficie, adhesión, superficie de soporte horizontal. Estas nociones tienden a ser candidatas a universales semánticos en el subdominio topológico, y no los conceptos ON e IN, los cuales están ellos mismos composicionalmente construidos.

\section{Construcción locativa con verbos posicionales}

En toba del oeste de Formosa la construcción locativa que puede ser utilizada en la descripción de todas las escenas topológicas en el corpus analizado está compuesta por un verbo en cuya raíz se codifica la posición de la figura y, mediante sufijos locativos, se expresa la relación topológica entre la figura y el fondo. Además, ocurre, en posición postverbal, una frase nominal que codifica el fondo; la expresión de la figura como frase nominal plena es opcional. En (1) ocurre la raíz posicional ne 'sentarse' junto al sufijo aspectual -ta 'imperfectivo, no progresivo' y los sufijos locativos tipo $1 \tilde{n} i$ 'hacia abajo' y tipo 2 -gi 'dentro, contención parcial', la frase nominal dírme noGóp 'el agua', pospuesta al verbo, codifica el fondo, y la frase nominal hañípme nelikotá 'el barco' que expresa la figura es omitida en la respuesta, puesto que su referente puede ser anafóricamente identificado en la pregunta. 
(1)

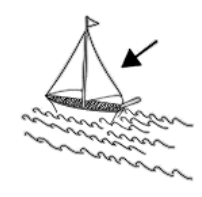

\begin{tabular}{|c|c|c|c|}
\hline háyga? & $\emptyset$-né-ta-ña & ha-ñí?-me & nelikotá \\
\hline INTER & 3l-sentarse-nprog-LOC1.LOC2 & F-DSE-ENDOF & barco \\
\hline ¿¿Dónde & ntado el barco?’ & & \\
\hline qa? & $\emptyset$-né-ta-yngi & dî́-me & noGóp \\
\hline coord & 3l-sentarse-NPROG-LOC1.LOC2 & DACOS-ENDOF & Agua \\
\hline
\end{tabular}

En el cuadro 3 se esquematiza la información topológica y la flexión de persona y número en los verbos posicionales en la lengua estudiada.

\begin{tabular}{|c|c|c|c|c|c|c|}
\hline Figura & $\begin{array}{l}\text { Posición } \\
\text { de la figura }\end{array}$ & Figura & Estático & Figura & $\begin{array}{l}\text { Relación espacial } \\
\text { entre figura } \\
\text { y fondo (singular) }\end{array}$ & $\begin{array}{c}\text { Relación espacial } \\
\text { entre figura } \\
\text { y fondo (plural) } \\
\end{array}$ \\
\hline $1 s g h-$ & we 'acostarse' & & $(-t a)$ & & -lege & I-lote \\
\hline $2 \mathrm{sg} 0-$ & & & & & - ?ot & -0 \\
\hline $35 g \varnothing-$ & & & & & $-\tilde{n} a$ & -10 \\
\hline $1 \mathrm{gh-}$ & & $-q$ & & & $-y i$ & -10 \\
\hline 1gr -- & & & & & & \\
\hline $2 \mathrm{pl} \mathrm{o-}$ & & $-i$ & & & -we & -10 \\
\hline 3pl $\varnothing-$ & & & & $-d$ & -ingi & -10 \\
\hline
\end{tabular}

Cuadro 3. Verbos con raíces posicionales: información topológica y flexión de persona y número.

Si bien los estudios que abordan íntegramente el análisis de la estasis no angular en lenguas guaycurúes son escasos, en las gramáticas descriptivas se incluye información acerca de la morfosintaxis de los verbos posicionales y es posible observar diferencias en la flexión pronominal y la segmentación morfema a morfema. En toba del oeste de Formosa, los verbos posicionales codifican la posición de la figura y reciben flexión de persona y número a través de los índices pronominales tipo I (cuadros 1 y 3 ) de manera independiente de la raíz posicional en todo el paradigma pronominal y siempre ocurren junto a sufijos locativos. En el vocabulario de la variedad de toba hablada en Misión El Toba de Sombrero Negro - misión anglicana, próxima al río Pilcomayo de donde migraron a su localización actual los tobas del oeste formoseño-, Tebboth $(1943,94)$ incluye el uso de las raíces posicionales $u e^{2}$ y né definidas como 'estar en una posición echada' y 'estar en una posición no echada', respecti2. Se mantiene la notación utilizada por los autores consultados. vamente, con flexión de persona sin sufijos locativos ni aspectuales adicionales (cuadro 4).

\begin{tabular}{|llll|}
\hline ué 'estar en una posición echada' & & sg & $\mathrm{pl}$ \\
& 1 & joué & jouacá \\
& 2 & oué & ovíya \\
& 3 & ué & ued \\
\hline
\end{tabular}




\begin{tabular}{|llll|}
\hline né 'estar en una posición no echada' & & sg & pl \\
& 1 & joné & jonacá \\
& 2 & oné & oñiya \\
& 3 & né & ned \\
\hline
\end{tabular}

Cuadro 4. Raíces posicionales con flexión de persona y número en toba de Sombrero Negro (Tebboth 1943, 94).

En cambio, en toba de la provincia de Chaco, Censabella (2002, 186-187) describe en los verbos posicionales los prefijos $n$ - y $w$ - como marcadores de tercera persona que permiten distinguir, además, una alternancia entre voz media - posición más permanente- y activa — posición temporaria-, respectivamente. Por su parte, Messineo y Klein (2007, 133-136) plantean en esta variedad de toba una amalgama del marcador de persona y la raíz del verbo locativo y analizan las raíces $w(e)-/ n(e)$ - como constituyentes de la construcción locativa básica junto al "sufijo de aspecto continuo (durativo) -ta y uno o más de los sufijos direccionales". Distinguen el uso de dichas raíces según el referente de la figura sea percibido como: (i) w(e)- "alargado o extendido horizontalmente en el espacio" o si se trata de una locación temporaria; o (ii) n(e)- en "su dimensión tridimensional o sentado" o si se trata de una locación permanente. En pilagá, Vidal $(2001,237,256)$ describe a neta como un verbo cópula y al morfema $w$-como índice pronominal verbal. Por ejemplo, w-eta-ge' 'está en un lugar distante'. En mocoví, Carrió (2011, 7, 13-14, 18-19; 2015, 111) presenta las raíces ne- y ve- como existenciales ${ }^{3}$, no amalgamadas con los índices pronominales verbales. Por ejemplo, en tercera persona singular ne-?ot 'está debajo de algo' yve-ta-lek 'está arriba de algo'.

\subsection{Raíces posicionales}

En el corpus analizado, las raíces posicionales ne y we, y sus alomorfos na y wa son traducidas al español como 'sentarse' y 'acostarse', respectivamente, y no como 'estar sentado/a' y 'estar acostado/a', puesto que el carácter estativo no es proporcionado por la raíz verbal misma, sino mediante el uso del sufijo aspectual -ta 'imperfectivo, no progresivo'. La posición 'parado/a' se expresa a través del lexema nechatétañi 'está parado/a', cuya flexión de persona y número de sujeto corresponde a los índices pronominales tipo II. Por ejemplo, en primera persona singular es ñichatétañi 'estoy parado/a'. En cambio, los verbos posicionales ne 'sentarse' y we 'acostarse' ocurren con índices pronominales tipo I en los cuales, por ejemplo, la tercera persona es $\varnothing$ - y la primera persona singular $h$ - (cuadros 1 y 3 ).

No se observó el uso de las raíces posicionales ne'sentarse' y we 'acostarse' sin sufijos locativos. Sí se las registró, con o sin el sufijo aspectual -ta to -te 'imperfectivo, no progresivo'. Cuando la figura es animada, la alternancia en el uso del morfema aspectual habilita o no una lectura estativa del predicado ${ }^{4}$. En (2a) el uso del sufijo -ta 'imperfectivo, no progresivo' implica un estado en el que la figura permanece sentada en el fondo, mientras que en (2b), en ausencia de dicho sufijo, la escena es descripta como incoativa.
3. En mocoví, el lexema ve puede funcionar sin sufijos locativos como predicado existencial afirmativo (Carrió 2015,105). En toba del oeste de Formosa, el predicado existencial afirmativo es wo? y no se registró el uso de la raíz verbal we sin sufijos locativos.

4. Una alternancia similar fue descripta, por ejemplo, por Newman $(2002,4)$ en usan (familia papú, Papúa Nueva Guinea), donde los verbos de postura dinámicos son básicos y los significados estativos son derivados a partir de los verbos dinámicos en aspecto continuativo. 
(2)

a.

$\begin{array}{llllll}\text { qa? } & \varnothing \text {-ne-ta-lége } & \text { l-aeñí } & \text { ha-ná?-me } & \text { epáq } & \text { l-epé? } \\ \text { COORD } & \text { 3l-sentarse-NPROG-Loc2 } & \text { 3POs-medio } & \text { F-DAC-ENDOF } & \text { árbol } & \text { 3Pos-rama } \\ \text { 'Está sentado en el medio de la rama del árbol (se quedó ahí sentado)'. } & \end{array}$

b.

Ø-na-lé di? epáq

3l-sentarse-LOC2 DACOS árbol

'Se sentó en el árbol'.

En las descripciones de las escenas que componen el estímulo visual Topological Relations Picture Series (Bowerman y Pederson 1992) proporcionadas por los hablantes consultados se observó una tendencia a utilizar verbos locativos sin el morfema de aspecto no progresivo -ta cuando la figura es inanimada y se encuentra adherida al fondo, es decir, es menos movible e independiente del mismo. Por ejemplo, letras en una remera (3), rajadura en una taza, mancha en una tela, manija en una puerta y cinta en una vela.

(3)

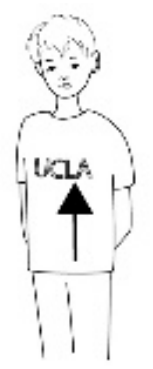

$\begin{array}{llll}\text { háyga? } & \emptyset \text {-wá-P̃̃a } & \text { dá?-me } & \text { l-edáGat } \\ \text { INTER } & \text { 3l-acostarse-LOC1.LOC2AB.AL } & \text { DPA-ENDOF } & \text { 3POs-letra } \\ \text { dá?-me } & \text { n-ohómaGaki } & \text { ho? } & \text { noGotolé-k } \\ \text { DPA-ENDOF } & \text { 3POs-remera } & \text { DAL } & \text { niña-MASC } \\ \text { ‘¿Dónde se acuesta la letra de la remera del niño?’ } & \\ \text { qa? } & \emptyset \text {-wa-lége } & \text { ha-dá?-me } & \text { l-etóge } \\ \text { COORD } & \text { 3l-acostarse-LOC2 } & \text { F-DPA-ENDOF } & \text { 3POs-pecho } \\ \text { dá?-me } & \text { n-ohómaGaki } & & \\ \text { DPA-ENDOF } & \text { 3POs-remera } & \\ \text { 'Se acuesta sobre el pecho de la remera' (TRPS 68). }\end{array}$

La selección de las raíces posicionales ne 'sentarse' y we 'acostarse', en el corpus recolectado, está condicionada por distintos factores:

(i) La "zona activa" (Newman 2002) de la figura en la escena descripta, es decir la parte de la figura que está en contacto con el fondo. Si la figura es animada, cuando las nalgas o la base de estas están en contacto con el fondo, se selecciona la raíz posicional ne 'sentarse' (4a). En cambio, cuando la zona activa es un lado de la figura distinto de la base o las nalgas, se selecciona we 'acostarse' $(4 b)^{5}$. 
(4)

a.

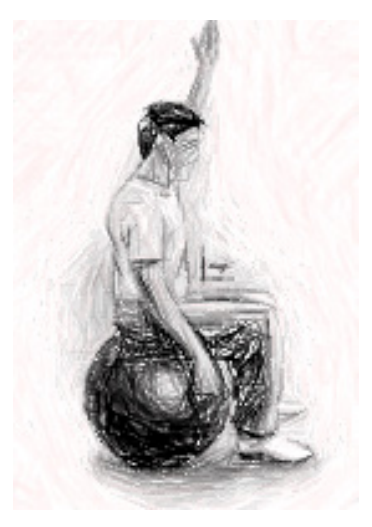

$\emptyset$-ne-ta-lége

3l-sentarse-NPROG-LOC2

pelóta

pelota

'Está sentado sobre la pelota'. b.

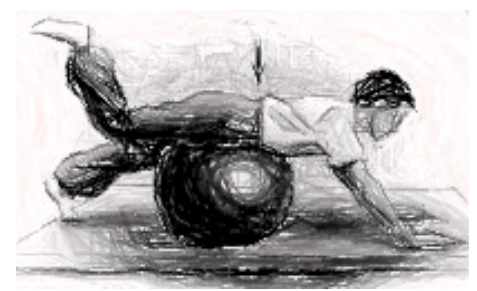

$\emptyset$-we-ta-lége pelóta

3l-acostarse-NPROG-LOC2 pelota

'Está acostado sobre la pelota'.

En la selección de las raíces posicionales resulta fundamental el hecho de si la base de la figura se encuentra apoyada en el fondo o en dirección al mismo (ne 'sentarse') o no (we 'acostarse'). A su vez, la alternancia de verbo posicional expresa un cambio en lo que respecta a la sujeción de la figura al fondo. Cuando la figura está fuertemente sujetada, ocurre la raíz posicional ne 'sentarse', como se observa en la descripción de la escena topológica 41 (5a). En cambio, si las hojas solo estuvieran apoyadas en la rama del árbol, es decir, cuando la sujeción es débil, se selecciona we 'acostarse' $(5 b)^{6}$.

6. Un impacto en el grado de sujeción de la figura al fondo dependiendo del verbo posicional seleccionado tam bién fue descripto, por ejemplo, en yélî dnye (Aislada, Papúa Nueva Guinea) por Levinson (2006, 172-173): sujeción fuerte cuando se selecciona el verbo t:a 'colgado (hanging)' y débil cuando

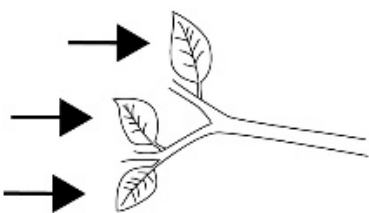
ocurre el verbo tóó 'sentado (sitting)'.

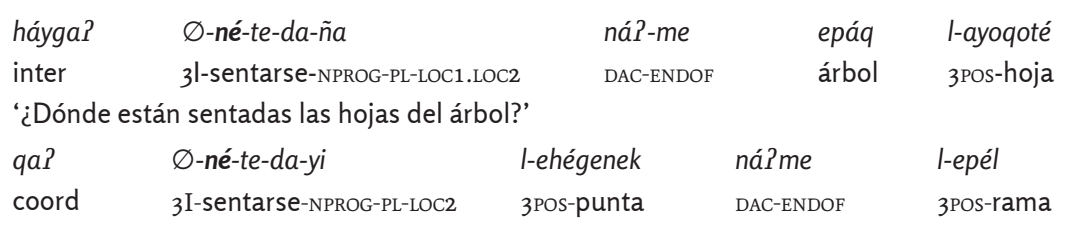

'Están sentadas sobre la punta de su rama' (TRPS 41).

b.

$\begin{array}{llll}\varnothing \text {-wé-te-da-yi } & \text { l-ehégenek } & \text { ná?me } & \text { l-epél } \\ \text { 3I-acostarse-NPROG-PL-LOC2 } & \text { 3Pos-punta } & \text { DAC-ENDOF } & \text { 3Pos-rama }\end{array}$

'Están acostadas (sueltas pero apoyadas) en la punta de su rama'.

(ii) La forma de la figura. Cuando la figura posee un eje (horizontal o vertical) prominente, se selecciona la raíz we 'acostarse' (6)-(7). 
(6)

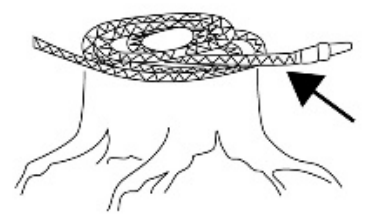

\begin{tabular}{|c|c|c|c|}
\hline háyga? & $\varnothing$-wé-ta-ña & hó?-me & nanáyk \\
\hline inter & 3l-acostarse-NPROG-LOC1.LOC2 & DEM-ENDOF & víbora \\
\hline \multicolumn{4}{|c|}{ ‘¿Dónde está acostada la víbora?’ } \\
\hline$q a ?$ & $\varnothing$-wé-ta-yngi & l-aeñí & ha-ñí?-me \\
\hline coord & 3l-acostarse-NPROG-LOC1.LOC2 & 3Pos-medio & F-DEM-ENDOF \\
\hline epáGa & l-amó & & \\
\hline árbol & 3POs-tronco & & \\
\hline
\end{tabular}

(7)

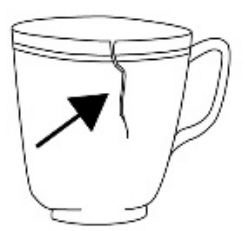

$\begin{array}{lllll}\text { háyga? } & \emptyset \text {-wá?-ña } & \text { l-eketáGa } & \text { ha-ñí-me } & \text { tá:do } \\ \text { INTER } & \text { 3l-acostarse-LOC1.LOC2 } & \text { 3POS-rajadura } & \text { F-DSE-ENDOF } & \text { taza }\end{array}$

‘¿Dónde está acostada la rajadura de la taza?’

$\begin{array}{llllll}\text { qa? } & \varnothing \text {-wá?-ña } & \text { dá?-me } & \text { l-áe } & \text { ha-ñíl-me } & \text { tá:do } \\ \text { COORD } & \text { 3l-acostarse-LOC1.LOC2 } & \text { DPA-ENDOF } & \text { 3POS-lado } & \text { F-DSE-ENDOF } & \text { taza }\end{array}$

'Está acostada en el costado de la taza' (TRPS 26).

En cambio, cuando la figura no posee un eje prominente, es decir, es compacta (con poca diferenciación en sus lados), o posee una amplia base en su posición canónica, se selecciona ne 'sentarse' (8).

(8)

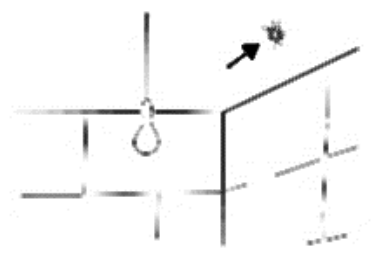

\begin{tabular}{|c|c|c|c|c|}
\hline háyga? & $\varnothing$-né-ta-ña & & há?-me & wachidíyaga \\
\hline INTER & 3l-sentarse-NPROC & 1.LOC2 & DAL.F-ENDOF & araña \\
\hline ¿¿Dónde $e$ & entada la araña?' & & & \\
\hline$q a ?$ & há?-me & wachidíyaga & $\varnothing$-né-ta-ña & \\
\hline COORD & DAL.F-ENDOF & araña & 3l-sentarse-NPRO & 1. LOC2 \\
\hline ná?-me & páhegem & & & \\
\hline DAC-ENDOF & arriba & & & \\
\hline
\end{tabular}


Las relaciones entre figura-fondo de vestimenta/ornamentación, por ejemplo, anillo en el dedo, zapato en el pie (9), cinturón en la cintura, vincha en la cabeza, y collar en el cuello, ocurren con el verbo posicional ne 'sentarse'.

(9)

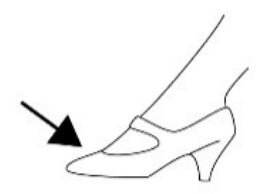

\begin{tabular}{|c|c|c|c|}
\hline háyga? & $\emptyset$-né-ta-ña & hó?-me & pelá \\
\hline INTER & 3l-sentarse-NPROG-LOC1.LOC2 & DAL-ENDOF & zapato \\
\hline \multicolumn{4}{|c|}{ ‘¿Dónde está sentado el zapato?’ } \\
\hline$q a ?$ & $\varnothing$-né-ta-yi & dá?-me & n-ápya? \\
\hline COORD & 3l-sentarse-NPROG-LOC2 & DPA-ENDOF & 3IPOS-pie \\
\hline
\end{tabular}

\subsection{Sufijos locativos}

En los datos recolectados mediante las imágenes de Topological Relations Picture Series (Bowerman y Pederson 1992) se registró el uso de los siguientes sufijos locativos, los cuales pueden ser clasificados de acuerdo con distintas dimensiones semánticas:

(i) Relación vertical y contacto. El par -lege, 'sobre, con contacto, no adherido' (10), y - $\square$ ot, 'debajo, con o sin contacto, no adherido' (11).

(10)

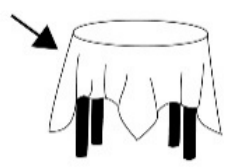

\begin{tabular}{|c|c|c|c|}
\hline háyga? & $\varnothing$-wé-ta-ña & ná?-me & l-ekóhogoki \\
\hline INTER & 3l-acostarse-NPROG-LOC1.LOC2 & DAC-ENDOF & 3Pos-mantel \\
\hline dî́-me & achágala & & \\
\hline DACOS-ENDOF & mesa & & \\
\hline \multicolumn{4}{|c|}{ ‘¿Dónde está acostado el mantel de la mesa?’ } \\
\hline$q a ?$ & $\varnothing$-wé-ta-lege & náP-me & l-achágala? \\
\hline COORD & 3l-acostarse-NPROG-LOC2 & DAC-ENDOF & 3Pos-mesa \\
\hline
\end{tabular}

(11)

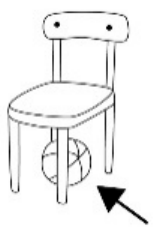

$\begin{array}{llll}\text { háyga? } & \varnothing \text {-né-ta-ña } & \text { ha-ñír-me } & \text { pelóta } \\ \text { INTER } & \text { 3l-sentarse-NPROG-LOC1.LOC2 } & \text { F-DSE-ENDOF } & \text { pelota }\end{array}$

‘¿Dónde está sentada la pelota?’ 
qa? $\quad$-ne-tó-?ot há?-me ho?ónagaki páñi

COORD 3l-sentarse-NPROG-LOC2 DAC-ENDOF silla debajo

'Está sentada abajo en la parte de abajo de la silla' (TRPS 16).

(ii) Contención. El par -we, 'adentro, totalmente contenido por el fondo, en medio de' (12), e -ingi, 'adentro, parcialmente contenido por el fondo' (13).

(12)

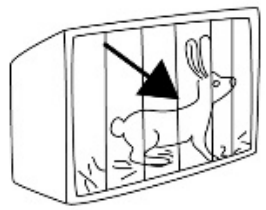

\begin{tabular}{|c|c|c|c|}
\hline $\begin{array}{l}\text { háyga? } \\
\text { INTER }\end{array}$ & $\begin{array}{l}\varnothing \text {-né-ta-ña } \\
\text { 31-sentarse-NPROG-LOC1.LOC2 }\end{array}$ & $\begin{array}{l}\text { ñíl-me } \\
\text { DSE-ENDOF }\end{array}$ & $\begin{array}{l}\text { nehe?ónaq } \\
\text { conejo }\end{array}$ \\
\hline \multicolumn{4}{|c|}{ ‘¿Dónde está sentado el conejo?’ } \\
\hline$q a ?$ & $\varnothing$-né-ta-we & ha-dár-me & I-áet \\
\hline OORD & 31-sentarse-NPROG-LOC2 & F-DPA-ENDOF & 3Pos-recipiente \\
\hline
\end{tabular}

(13)

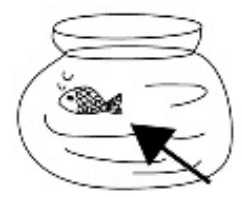

\begin{tabular}{|c|c|c|c|c|}
\hline háyga? & $\varnothing$-wé-ta-ña & dí?-me & níyaq & qóGot \\
\hline INTER & 3l-acostarse-NPROG-LOC1.LOC2 & DACOS-ENDOF & pescado & pertenencia \\
\hline \multicolumn{5}{|c|}{ ‘¿Dónde está acostado el pececito?’ } \\
\hline$q a ?$ & $\varnothing$-wé-ta-yngi & & ha-ñí?-me & matiyiyá \\
\hline COORD & 3l-acostarse-NPROG-LOC1.LOC2 & & F-DSE-ENDOF & vidrio \\
\hline
\end{tabular}

(iii) Adhesión a través de perforación u otros medios. En -yi, 'adherido al fondo' (14).

(14)

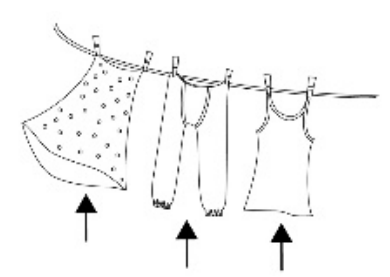

háyga?

$\varnothing$-né-te-da-ña

INTER 3l-sentarse-NPROG-PL-LOC1.LOC2

$\tilde{n}<a ́>$ ?-me $\quad \tilde{n}$-iyó-ts

‘¿Dónde están sentadas mis ropas recién lavadas?'
qa?
$\varnothing$-né-te-da-yi
COORD
3l-sentarse-NPROG-PL-LOC2
dí?-me
ñik
DACOS-ENDOF piola

‘Están sentadas, puestas sobre la piola' (TRPS 37 ). 
(iv) Contacto y suspensión (hanging). En -hegem, 'arriba' (este sufijo no requiere la codificación del nominal que expresa el fondo) (cuadro 2) (15) ${ }^{7}$.

(15)

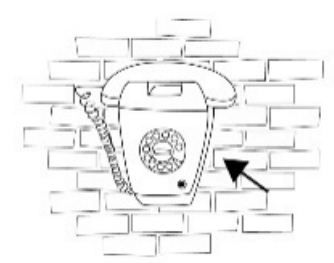

háyga? Ø-né-ta-ña

INTER 3l-sentarse-NPROG-PL-LOC1.LOC2

‘¿Dónde está sentado el teléfono?’

qa? Ø-né-ta-hegem,

COORD 3l-sentarse-NPROG-LOC1

emék l-ae

casa 3 Pos-lado

'Está sentado arriba (está colgado), está sentado en la pared' (TRPS 25).

(v) Contigüidad en general. En -ña, 'hacia abajo + hacia algo' (16). Los sufijos locativos tipo 1 -ñi 'hacia abajo' y tipo 2 -a 'hacia algo' pueden ser considerados como locativos generales, puesto que son los que ocurren en las preguntas ¿̇dónde está X?, implican solo contigüidad y habilitan la respuesta deseada sin condicionar al oyente respecto de una relación locativa determinada. Esta característica se ve reforzada por el hecho de que las raíces posicionales junto a estos sufijos ocurren siempre que son utilizadas como respuesta a la pregunta ¿dónde está X? junto a los lexemas laeñí 'su mitad, medio' (16), lae 'su lado, costado', lahót 'su medio, torso', ypáhegem 'arriba', entre otros, que especifican la región del fondo en la que se ubica la figura (\$5.3).

(16)

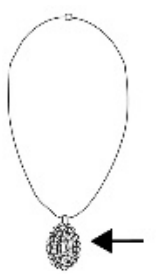

\begin{tabular}{lllll} 
háyga? & $\varnothing$-né-ta-ña & ha-ñí?-me & \multicolumn{2}{c}{ qolá } \\
INTER & 3l-sentarse-NPROG-LOC1.LOC2 & F-DSE-ENDOF & bolita, perla \\
¿¿Dónde está sentada la bolita/perla?’ & & & \\
qa? & $\varnothing$-né-ta-ña & l-aeñí & ná?-me & l-ekét \\
COORD & 3l-sentarse-NPROG-LOC1.LOC2 & 3POS-medio & DAC-ENDOF & 3POS-Cordón
\end{tabular}

‘Está sentada en el medio del cordón' (TRPS 57).

\subsection{Lexemas espaciales}

A su vez, en la construcción locativa con verbos posicionales pueden ocurrir los lexemas espaciales páwo 'adentro', páyi 'afuera', páñi 'abajo', páhegem 'arriba', lae lay 'su lado, costado', y laeñí layñí 'su mitad, medio'. Estos lexemas dan cuenta de una relación meronímica, de parte-todo, o de una locación relativa, según ocurran inmediatamente pospuestos a la frase nominal que codifica el fondo o al verbo locativo, respectivamente ${ }^{8}$.
7. Otras relaciones topológicas en las que se utiliza el sufijo-hegem 'arriba' son: saco en un perchero, cuadro en la pared, ropa en el tendal, y globo suspendido en la punta de un palo.
8. La yuxtaposición de frases nominales (nombre $+l$-nombre) para expresar una relación de posesión y/o de tipo meronímica (parte/todo) es un recurso utilizado en la lengua estudiada que no se restringe a las construcciones locativas con verbos posicionales (Carpio 2012, 90-94). A su vez, fue analizada en las variedades orientales de toba, especialmente de la provincia de Chaco, por Klein (2000, $85)$, Censabella $(2002,277)$ y Messineo (2003, 133), y con especial referencia al léxico etnobotánico por Cúneo (2013, 241-247), y Martínez y Cúneo (2009). 
En (17) se ilustra el alcance diferencial del lexema lae 'su costado, lado' y su impacto en el significado de la construcción locativa, según ocurre inmediatamente pospuesto a la frase nominal fondo nárme emék 'la casa' (17a) o al verbo locativo wétaña 'está acostada' (17b). En (17a) lae 'su costado, lado' especifica una parte del fondo 'el costado de la casa, la pared', es decir no trasciende sus límites. En cambio, en (17b) lae 'su costado, lado' permite situar la figura en relación con el fondo sin referirse a una parte de este último.

(17)

a. Parte espacial

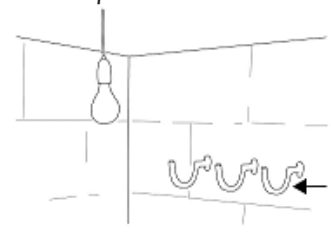
$q a ?$
$\varnothing$-né-te-da-yi
ná?-me
emék
l-ae
COORD
3I-sentarse-NPROG-PL-LOC2
DAC-ENDOF
casa
3Pos-lado

'Están sentados (puestos) (los ganchos) en la pared (el lado de la casa)' (TRPS 50).

b. Relación espacial

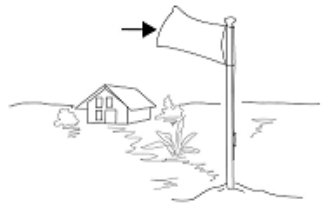

$\begin{array}{llccc}\text { qa? } & \varnothing \text {-wé-ta-ña } & \text { l-ae } & \tilde{n} i ́ \text {-me } & \text { emék } \\ \text { COORD } & \text { 3l-acostarse-NPROG-Loc1.Loc2 } & \text { 3Pos-lado } & \text { DSE-ENDOF } & \text { casa } \\ \text { 'Está acostada (puesta) (la bandera) al costado de la casa' (TRPS 56). }\end{array}$

En (18) el lexema páñi 'debajo' ocurre pospuesto a la frase nominal que codifica el fondo, especificando una parte de este (18a), y pospuesto al verbo locativo, expresando la localización de la figura respecto del fondo (18b).

(18)

a. Parte espacial

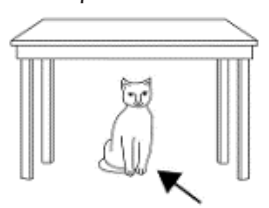

qa?

$$
\varnothing \text {-ne-tó-?ot }
$$

ná?-me

achágala?

páñi

COORD

3I-sentarse-NPROG-LOC2

DAC-ENDOF

mesa 9

debajo

'Está sentado (el gato) debajo en la parte de abajo de la mesa' (TRPS 31).

b. Relación espacial

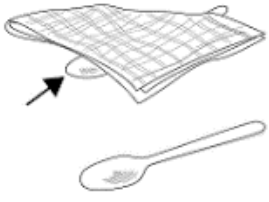

qa?

$$
\text { Ø-we-tó-?ot }
$$

ná?-me

páñi ná?-me

n-ogonék

COORD

3I-acostarse-NPROG-LOC2

DAC-ENDOF

debajo DAC-ENDOF

3Pos-alfombra

'Está acostada (la cuchara) debajo de la alfombra' (TRPS 24). 
De este modo, los lexemas espaciales, de acuerdo con el constituyente de la cláusula al cual se posponen, se refieren a una parte del fondo o codifican una relación locativa. El ejemplo (19) resulta particularmente interesante, puesto que ilustra cómo el lexema páhegem 'arriba', inmediatamente pospuesto a la frase nominal que codifica el fondo (náime emék 'casa'), especifica una parte de este ('la parte de arriba de la casa, el techo'). Sin embargo, la figura está ubicada debajo del fondo tal como es codificado mediante el sufijo locativo tipo 2 -?ot 'debajo de' en el verbo.

(19)

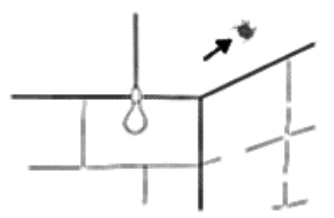

$\begin{array}{lllll}h<a ́>\text { ?-me } & \text { wachidíyaga } & \text { qa? } & \varnothing \text {-ne-tó-?ot } & \text { ná?-me } \\ \text { DAL<F>-ENDOF } & \text { araña } & \text { COORD } & \text { 3I-sentarse-NPROG-LOC2 } & \text { DAC-ENDOF } \\ \text { emek } & \text { páhegem } & & & \\ \text { casa } & \text { arriba } & & & \end{array}$

‘La araña está sentada debajo de la parte de arriba de la casa (el techo)' (TRPS7).

En ocasiones, toda la información topológica de la cláusula es expresada por el lexema espacial junto al nombre que codifica al fondo (20)-(21).

(20)

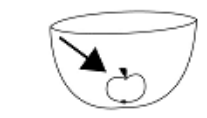

$\begin{array}{llll}\text { qa? } & \text { l-ayñí } & \text { ha-ná?-me } & \text { taGakí } \\ \text { COORD } & \text { 3POS-medio } & \text { F-DAC-ENDOF } & \text { olla }\end{array}$

'En el medio de la olla' (TRPS 2).

(21)

$\begin{array}{llll}\text { qa? } & \text { páwo } & \text { ha-ná?-me } & \text { tagakí } \\ \text { COORD } & \text { adentro } & \text { F-DAC-ENDOF } & \text { olla }\end{array}$

'Adentro de la olla' (TRPS 2).

En lo que respecta al estatus categorial de los lexemas espaciales lae lay 'su lado, costado' y laeñí layñí 'su mitad, medio' en la lengua estudiada, se trata de nombres inalienables. Además de estos dos nombres, fueron registrados, hasta el momento, los siguientes nombres de partes del cuerpo utilizados con el fin de especificar en qué subregión del fondo se ubica la figura (22):

(22)

\begin{tabular}{ll}
\hline Parte del cuerpo & Locación \\
\hline leketéla 'su oreja' & (en la) esquina de algo \\
lahót 'su torso' & (en el) medio, mitad de algo \\
lehégenek 'su punta' & (en la) punta, en el extremo de algo \\
nedéyacat 'su boca' & (en la) boca de algo (botella, por ejemplo) \\
letóge 'su pecho' & (en el) pecho de algo (camisa, por ejemplo) \\
\hline
\end{tabular}


Por ejemplo, en (23), la posición de la estampilla en el sobre es codificada a través del lexema leketéla 'su oreja' yuxtapuesto a la frase nominal que codifica el fondo hanárme nedélae 'su papel'.

(23)

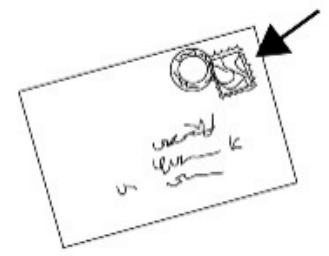

\begin{tabular}{|c|c|c|c|c|c|}
\hline háyga? & Ø-ná-ña & ná?-me & l-iyodágat & ha-ná?-me & n-edélae \\
\hline & 3l-sentarse-LOC1.LOC2 & DAC-ENDOF & 3Pos-figura & F-DAC-ENDOF & 3POS \\
\hline
\end{tabular}

‘¿Dónde se sienta la figura del papel?’

$\begin{array}{llll}\text { qa? } & \text { l-eketéla } & \text { ha-náP-me } & \text { n-edélae } \\ \text { COORD } & \text { 3POS-oreja } & \text { F-DAC-ENDOF } & \text { 3POS-papel }\end{array}$

'En la oreja o esquina del papel’ (TRPS 3 ).

En cambio, el estatus categorial de los lexemas espaciales páwo 'adentro', páyi 'afuera', páñi 'abajo', y páhegem 'arriba' requiere ser analizado en profundidad en futuros trabajos puesto que, sincrónicamente, poseen compatibilidades sintagmáticas que los acercan a los nombres, como por ejemplo ocurrir junto a los demostrativos sin morfología adicional y, a su vez, pueden recibir flexión de persona y número de sujeto a la manera de los verbos (cuadro 5).

\begin{tabular}{|c|c|c|c|c|}
\hline \multirow[b]{3}{*}{1} & SINGULAR & \multicolumn{2}{|c|}{ NO-SINGULAR } & \\
\hline & & Grupo & $\begin{array}{l}\text { Grupo } \\
\text { restringido }\end{array}$ & \\
\hline & h-epáhegem & h-epá-Ga-hegem & qa-páhegem & $\begin{array}{c}1+2 \\
1+2+3 \\
1+3\end{array}$ \\
\hline 2 & a-páhegem & a-pá-yi-hegem & & $2+3$ \\
\hline 3 & $\emptyset$-páhegem & & $\emptyset$-pá-di-hegem & $3+3$ \\
\hline
\end{tabular}

Cuadro 5. Flexión de persona y número en lexema espacial páhegem ‘arriba, estar arriba’.

\section{Otras estrategias morfosintácticas locativas}

Además de la construcción locativa descripta en §5, los hablantes utilizaron otras estrategias morfosintácticas, especialmente verbos alternativos a los posicionales, para describir las escenas de Topological Relations Picture Series (Bowerman y Pederson 1992). Al aumentar el contacto por adhesión de la figura al fondo se tiende a utilizar, en la lengua estudiada, distintos verbos cuando la figura se encuentra adherida al fondo por medios que no implican perforación (con pegamento, por ejemplo) (24a), mediante perforación y suspendida en el aire (24b), o apoyada/inclinada contra el fondo (25).

La figura de la escena topológica en (24) fue descripta como una goma de mascar por uno de los hablantes y como un clavo por otro. En este sentido, se describieron dos escenas de adhesión distintas: (i) adhesión mediante pegamento debajo del fondo por lo que se seleccionó el verbo qapaltóiot 
'está adherido mediante una sustancia adherente debajo de' (24a); y (ii) adhesión mediante perforación sin soporte inferior, por lo que se optó por el verbo netaGát?añi 'está perforado y colgado' más una construcción existencial (24b).

(24)

a.

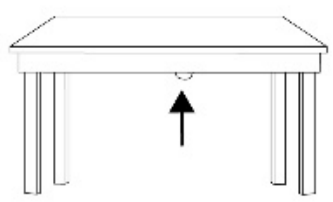

$\begin{array}{lllll}\text { háyga? } & \varnothing \text {-né-ta-ña } & \text { ha-ñíp-me } & \text { chíkle } & \\ \text { INTERR } & \text { 3l-sentarse-NPROG-AB.AL } & \text { F-DSE-ENDOF } & \text { chicle } & \\ \text { ‘¿Dónde está sentado el chicle?’ } & & & \\ \text { qa? } & \varnothing \text {-qapal-tó-Pot } & \text { ná?-me } & \text { páñi } & \text { achácala? } \\ \text { COORD } & \text { 3l-adherirse-NPROG-DEB } & \text { DAC-ENDOF } & \text { debajo } & \text { mesa }\end{array}$

'Está adherido, pegado debajo de la mesa' (TRPS 53 ).

b.

wo? gá?-me páñi Ø-netacát?añi l-eyaGaehté

EXIST DNP-ENDOF debajo 3l-perforar.colgar 3POs-clavo

'Hay debajo, perforado y colgado un clavo' (TRPS 53).

Los hablantes consultados utilizaron el verbo waqatalége 'está apoyado sobre' en la descripción de la escena en la que la figura es una escalera apoyada sobre la pared (25).

(25)

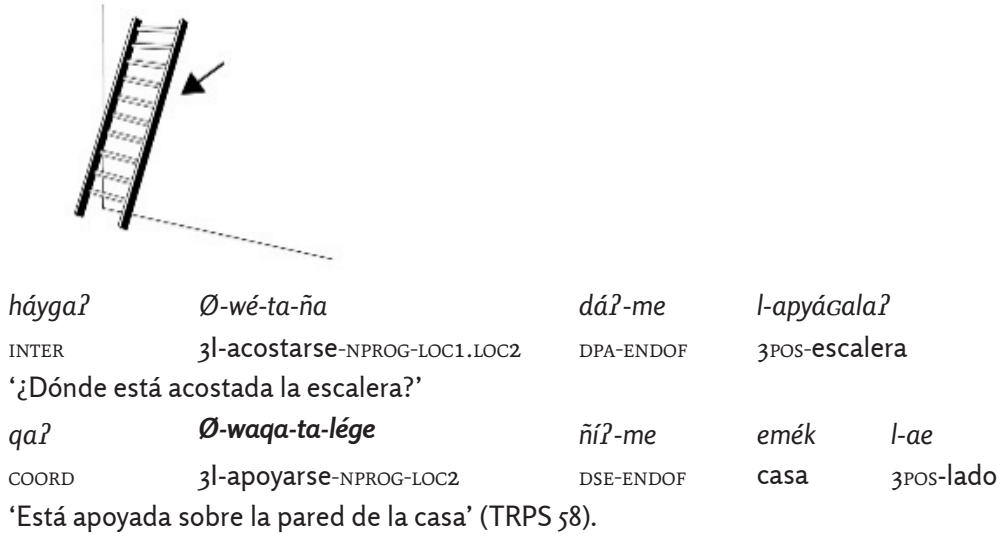

Otra escena topológica en la que es posible utilizar un verbo alternativo a las raíces posicionales, es aquella en la que la figura es un hombre parado sobre el techo de una casa y ocurre el verbo pe 'pisar' (26). 
(26)

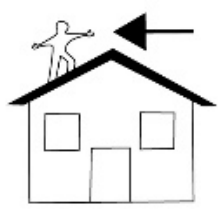

$\begin{array}{lccc}\emptyset \text {-pe-ta-lége } & \text { ná?-me } & \text { emék } & \text { páhegem } \\ \text { 3l-pisar-NPROG-LOC2 } & \text { DAC-ENDOF } & \text { casa } & \text { arriba } \\ \text { '(El hombre) está de pie sobre el techo de la casa' (TRPS 34). }\end{array}$

Se registró, además, el uso de la construcción existencial afirmativa en escenas que implican adhesión sin perforación tales como zapato en un pie, hojas en un árbol, letras en una remera (27).

(27)

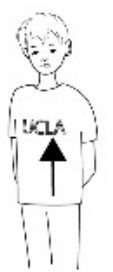

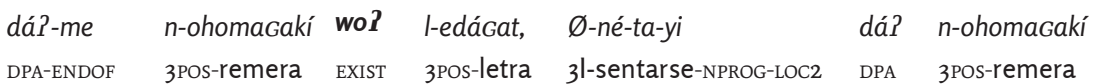

'La remera tiene una letra impresa, está sentada en la remera' (TRPS 68).

En la escena en la que la figura es una manzana y el fondo una flecha que la perfora, además de la construcción locativa con el verbo posicional ne 'sentarse' (28a), los hablantes utilizaron el verbo transitivo yihóyiyi ‘hinca' (28b).

(28)

a.

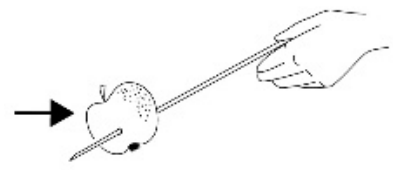

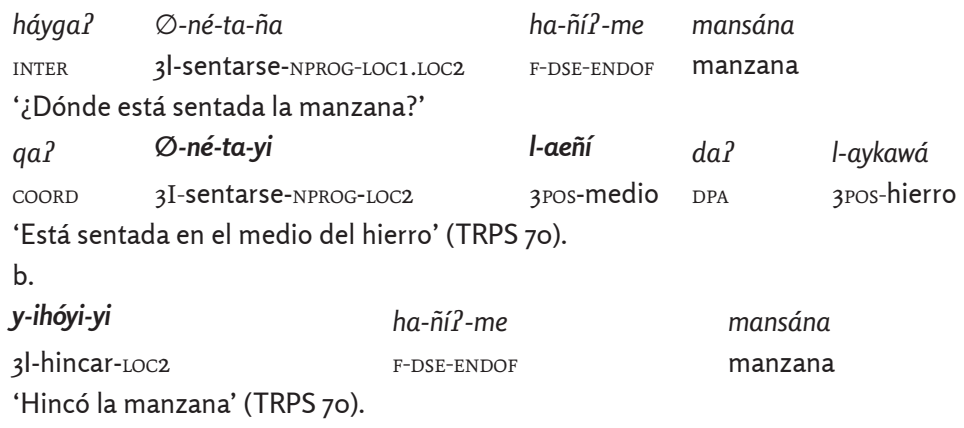




\section{Reflexiones finales}

En este trabajo se analizaron las construcciones morfosintácticas que se utilizan para codificar relaciones topológicas, es decir, en las que la figura y el fondo están en contigüidad o en gran proximidad, y en las cuales las distinciones angulares no son requeridas ni relevantes en toba del oeste de Formosa. Se describieron las construcciones locativas en las que ocurren las raíces posicionales ne 'sentarse' y we 'acostarse' y que son utilizadas para codificar todas las relaciones topológicas. Se demostró que la selección de estas raíces posicionales está condicionada por la "zona activa" (parte de la figura que está en contacto con el fondo) y la forma de la figura: la raíz posicional ne 'sentarse', ocurre cuando las nalgas o la base de la figura están en contacto con el fondo o si la figura es compacta o posee una amplia base en su posición canónica; mientras que la raíz posicional we 'acostarse' se selecciona cuando la "zona activa" es un lado de la figura distinto de la base o si la figura posee un eje (horizontal o vertical) prominente. En las construcciones locativas con verbos posicionales, se analizó, además, el uso de los lexemas espaciales páwo 'adentro', páyi 'afuera', páñi 'abajo', páhegem 'arriba', lae lay 'su lado, costado', y laeñí layñí 'su mitad, medio', los cuales, según ocurran inmediatamente pospuestos al nombre que codifica el fondo o al verbo locativo, permiten dar cuenta de una relación de partetodo o de una locación relativa, respectivamente. A su vez, se estudiaron estrategias morfosintácticas alternativas a las que se recurre al aumentar el contacto por adhesión de la figura al fondo, ya sea mediante una sustancia adherente o por perforación en suspensión, cuando la figura se encuentra inclinada sobre el fondo, o si la figura es una persona de pie sobre el fondo.

Los verbos y sufijos locativos seleccionados y las estrategias morfosintácticas alternativas utilizadas por los hablantes en la descripción del estímulo visual Topological Relations Picture Series (Bowerman y Pederson 1992) resultaron claves para identificar, en esta primera aproximación al estudio de la estructura del dominio semántico topológico en toba del oeste de Formosa, la relevancia de la zona activa y forma de la figura y de dimensiones tales como estasis, contacto, contención, posición vertical y adhesión. En este sentido, la descripción del subdominio topológico propuesta está en consonancia con lo planteado por Levinson y Wilkins (2006), desde una perspectiva translingüística, en el sentido de que son estas nociones intensionales las que tienden a funcionar como universales en el subdominio topológico.

En futuros trabajos, se profundizará el análisis en lo que respecta a la estasis angular y el movimiento con el fin de comparar los recursos gramaticales utilizados y las distinciones semánticas relevantes en cada subdominio semántico espacial en toba del oeste de Formosa. A su vez, la aplicación de los mismos estímulos visuales en otras lenguas del Gran Chaco sudamericano permitirá contar con un corpus de datos comparable regionalmente, y así contribuir al avance del conocimiento de la estructura del dominio semántico del espacio.

\section{Abreviaturas}

1, 2, 3=primera, segunda y tercera persona; $\mathrm{AB}=$ "hacia abajo'; cooRD=coordinante; DAC=demostrativo 'acercándose'; DACOs=demostrativo 'acostado'; DAL=demostrativo 'alejándose'; DEB=debajo; DPROX=demostrativo 'próximo'; DSE=demostrativo ‘sentado'; ENDOF=endofórico; DPA=demostrativo 'parado'; $\mathrm{F}=$ femenino; I=índice pronominal tipo I; INTER=interrogación; LOC1=locativo 1; LOC2=locativo 2; MASC=masculino; NPROG=aspecto no progresivo; PL=plural; POS=poseedor; RELA=relativo $\mathrm{a}$. 


\section{Q Bibliografía}

" Ameka, Felix. K. y Stephen C. Levinson. 2007. "Introduction. The typology and semantics of locative predicates: posturals, positionals, and other beasts". Linguistics 45.5: 847-871.

" Arenas, Pastor. 2003. Etnografía y alimentación entre los Toba-Ñachilamole\#ek y WichíLhuku'tas del Chaco Central (Argentina). Buenos Aires: edición del autor.

"Bowerman, Melissa y Eric Pederson. 1992. “Topological relations picture series”. En Space stimuli kit 1.2, editado por Stephen C. Levinson, Noviembre, 51. Nijmegen: Max Planck Institute for Psycholinguistics. Disponible en la página web del Max Planck Institute for Psycholinguistics: http://fieldmanuals.mpi.nl/volumes/1992/bowped/.

» Brown, Penelope. 2006. "A sketch of the grammar of space in Tzeltal”. En Grammars of Space. Explorations in Cognitive Diversity, editado por Stephen C. Levinson y David Wilkins, 230-272. Cambridge: Cambridge University Press.

"Buckwalter, Alberto. 1980. Vocabulario Toba. Seguido de algunos apuntes sobre la gramática del idioma toba. Roque Saénz Peña, Chaco, Argentina: edición del autor.

" Carpio, María Belén. 2011. "Morfosintaxis y usos pragmáticos de los demostrativos en toba ñachilamole?k (Formosa, Argentina)". En Investigaciones sobre lenguas indígenas sudamericanas, editado por Ana Fernández Garay y Antonio Díaz-Fernández, 19-40. Santa Rosa (La Pampa): Editorial de la Universidad Nacional de La Pampa.

"Carpio, María Belén. 2012. Fonología y morfosintaxis de la lengua hablada por grupos tobas en el oeste de Formosa (Argentina). LINCOM Studies in Native American Linguistics 67. München: LINCOM Europa Academic Publisher.

»Carpio, María Belén. 2014. “'Restricted group' and 'group' within the pronominal system of Western Toba (Guaicuruan, Argentina)”. Studies in language 38.4: 982-994.

" Carpio, María Belén. 2016. "Causativización de verbos locativos en toba del oeste de Formosa (guaycurú, Argentina)”. Lingüística. Asociación de Lingüística y Filología de América Latina (ALFAL) 32.2: 47-62.

》 Carpio, María Belén y Raúl Eduardo González. 2017. "Evidencialidad y modalidad epistémica en dos variedades de toba habladas en Formosa (Argentina)". Lexis 41.1: 121-147. Pontificia Universidad Católica de Perú.

" Carrió, Cintia. 2011. "Conflation in verbs of motion: construction of location and direction in the Mocoví language". Suvremena lingvistika 71: 1-25.

" Carrió, Cintia. 2015. "Morfosintaxis de las construcciones existenciales en mocoví (guaycurú)". RASAL. Revista de la Sociedad Argentina de Lingüística. 101-117.

"Censabella, Marisa. 2001. "Sincronía dinámica de los determinantes demostrativos en un corpus narrativo en lengua toba". Actas Cuartas Jornadas de Etnolingüística. Rosario: Escuela de Antropología. Universidad Nacional de Rosario.

"Censabella, Marisa. 2007. “Los aplicativos alativo y locativo en toba”. En Lenguas aborígenes de la Argentina. Aspectos lingüísticos y sociolingüísticos, editado por Ana Fernández Garay y Marisa Malvesttiti, 29-50. Santa Rosa: EdUNLPam.

»Censabella, Marisa. 2011. "Gramaticalización del aplicativo posicional -Pot en toba”. En Investigaciones sobre lenguas indígenas sudamericanas, editado por Ana Fernández Garay y Antonio Díaz-Fernández, 41-68. Santa Rosa: EdUNLPam.

"Cúneo, Paola. 2013. Formación de palabras y clasificación nominal en el léxico etnobiológico 
en toba (guaycurú). LINCOM Studies in Native American Linguistics 68. München: LINCOM Europa Academic Publisher.

" González, Raúl Eduardo. 2010. “Análisis sintáctico y semántico de dos aplicativos locativos en toba (familia guaycurú)". Lingüística. Revista de la Asociación de Lingüística y Filología de América Latina, 24: 123-140.

" González, Raúl Eduardo. 2011. "El comitativo y el recíproco en toba". En Investigaciones sobre lenguas indígenas sudamericanas, editado por Ana Fernández Garay y Antonio Díaz-Fernández, 143-168. Santa Rosa: EdUNLPam.

» González, Raúl Eduardo. 2015a. "Demostrativos pronominales y adnominales en toba del este de Formosa (Argentina)". Revista UniverSOS, 12: 147-162. Valencia: Universidad de Valencia.

"González, Raúl Eduardo. 2015b. Estudio fonológico y morfosintáctico de la lengua toba hablada en el este de la provincia de Formosa (Argentina). LINCOM Studies in Native American Linguistics 75. München: LINCOM Europa Academic Publishers.

» Gordillo, Gastón. 2006. En el Gran Chaco: Antropologías e historias. Buenos Aires: Prometeo.

» Grondona, Verónica. 1998a. "A Grammar of Mocoví". Tesis de doctorado, University of Pittsburgh.

" Grondona, Verónica. 1998b. “Location and Direction in Waikurúan Languages”. Annual Meeting of the Berkeley Linguistics Society, 24.1: 106-116.

" Gualdieri, Beatriz. 1998. "Mocovi (Guaicuru). Fonologia e morfossintaxe”. Tesis de doctorado, Universidade Estadual Campinas.

" Gualdieri, Beatriz. 2006. “Clasificadores guaycurúes: un desafío para la lingüística”. Actas del Encuentro de Lenguas Indígenas Americanas. La Pampa: Universidad Nacional de La Pampa.

» Klein, Harriet E. Manelis. 1981a. Una gramática de la lengua toba: morfología verbal y nominal. Montevideo: Dirección General de Extensión Universitaria.

" Klein, Harriet E. Manelis. 1981b. "Location and direction in Toba: verbal morphology". International Journal of American Linguistics, 47.3: 227-235.

"Klein, Harriet E. Manelis. 2000. "Meronymy or part-whole relations in indigenous languages of Lowland South America". En Essays on indigenous languages of Lowland South America. Contributions to the 49th International Congress of Americanists in Quito 1997, editado por Hein Van der Voort y Simon Van de Kerke, 83-98. Países Bajos: Universiteit Leiden.

"Klein, Harriet E. Manelis y Cristina Messineo. 2003. "Coherencia temporal en toba. Su continuidad en el contacto con el español". Memorias del Congreso de Idiomas Indígenas de Latinoamérica-I (CILLA 1). University of Texas at Austin. http://ailla.utexas.org/site/ cilla1. Fecha de consulta, 4 de abril de 2016.

"Levinson, Stephen C. 1996. "Language and space”. Annu. Rev. Anthropol., 25: 353-382.

"Levinson, Stephen C. 2006. “5. The language of space in Yélî Dnye”. En Grammars of Space. Explorations in Cognitive Diversity editado por Stephen C. Levinson y David Wilkins, 158-205. Cambridge: Cambridge University Press.

"Levinson, Stephen C. y David P. Wilkins. 2006. "1. The background to the study of the language of space", "14. Patterns in the data: towards a semantic typology of spatial description". En Grammars of Space. Explorations in Cognitive Diversity, editado por Stephen C. Levinson y David Wilkins, 1-23, 512-552. Cambridge: Cambridge University Press.

" Lillehaugen Brook, Danielle y Aaron Huey Sonnenschein (eds.). 2012. Expressing location in Zapotec. Muenchen: LINCOM Europa. 
» Martínez, Gustavo y Paola Cúneo. 2009. "Las denominaciones vernáculas y el conocimiento toba del entorno vegetal”. Revista de Dialectología y Tradiciones Populares (RDTP), 64.2: 149-168.

» Mendoza, Marcela y Pablo Wright. 1989. "Sociocultural and economic elements of the adaptation systems of the Argentine Toba: the Nacilamolek and Taksek cases of Formosa Province". En Archaeological approaches to cultural identity, editado por Stephen Shennan, 242-257. Londres: Unwin Hyman.

» Messineo, Cristina. 2003. Lengua toba (guaycurú). Aspectos gramaticales y discursivos. LINCOM Studies in Native American Linguistics 48. München: LINCOM Europa Academic Publisher.

" Messineo, Cristina. 2019. "Syntactic complexity and Grammaticalization in Toba Language”. En Diverse scenarios of syntactic complexity: inter and intra typological diversity, editado por Zarina Estrada Fernández, Albert Álvarez González y Claudine Chamoreau,191-216. Amsterdam/Philadelphia: John Benjamins Publishing Company.

» Messineo, Cristina y Harriet E. Manelis Klein. 2005. “Expresión de trayectoria en verbos de movimiento y posición en toba (flia guaycurú)". Memorias del Congreso de Idiomas Indígenas de Latinoamérica (CIILA). University of Texas at Austin. http://www.ailla.utexas. org/site/cillaz/MessineoKlein_CILLA2_toba.pdf. Fecha de consulta, 22 de abril de 2016.

» Messineo, Cristina y Harriet E. Manelis Klein. 2007. “Verbos de posición en toba (guaycurú)". En Lenguas indígenas de América del Sur: estudios descriptivo-tipológicos y sus contribuciones para la lingüística teórica, coordinado por Andrés Romero-Figueroa, Ana Fernández Garay y Ángel Corbera Mori, 127-144. Universidad Católica Andrés Bello.

» Najlis, Elena Lidia. 1966. Lengua abipona. Archivo de Lenguas Precolombinas 1. Buenos Aires: Facultad de Filosofía y Letras, Universidad de Buenos Aires.

"Newman, John. 2002. "A cross-linguistic overview of the posture verbs 'sit', 'stand' ad 'lie'”. En The linguistics of sitting, standing, and lying, editado por John Newman, 1-24. Amsterdam/Philadelphia: John Benjamins Publishing Company.

»Sandalo, Filomena. 1995. “A Grammar of Kadiwéu”. Tesis de doctorado, University of Pittsburgh.

»Senft, Gunter. 2000. Toward a Cognitive Semantics, II. MIT Press.

»Senft, Gunter. 2006. “6. Prolegomena to a Kilivila grammar of space”. En Grammars of Space. Explorations in Cognitive Diversity, editado por Stephen C. Levinson y David Wilkins, 206-229. Cambridge: Cambridge University Press.

» Talmy, Leonard. 1985. Lexicalization patterns: Semantic Structure in Lexical Form. En Language Typology and Syntactic Description Vol.3, editado por Timothy Shopen, 57-148. Cambridge: Cambridge University Press.

" Tebboth, Thomas. 1943. "Diccionario toba". Revista del Instituto de Antropología de Tucumán, 3.2:33-221.

»Van Staden, Miriam, Melissa Bowerman y Mariet Verhelst. 2006. "13. Some properties of spatial description in Dutch” En Grammars of Space. Explorations in Cognitive Diversity, editado por Stephen C. Levinson y David Wilkins, 475-511. Cambridge: Cambridge University Press.

» Vidal, Alejandra. 2001. “Pilagá Grammar (Guaykuruan Family, Argentina)”. Tesis de doctorado, University of Oregon. Oregon.

» Watkins, Laurel J. 1976. "Position in grammar: sit, stand, lie”. Kansas Working Papers in Linguistics, 1: 16-41.

» Wilkins, David P. 2006. "2. Towards an Arrernte grammar of space”. En Grammars of Space. Explorations in Cognitive Diversity, editado por Stephen C. Levinson y David Wilkins, 24-62. Cambridge: Cambridge University Press. 